\title{
Development of a 12-item short version of the HIV stigma scale
}

\author{
Maria Reinius ${ }^{1}$, Lena Wettergren ${ }^{2}$, Maria Wiklander ${ }^{2}$, Veronica Svedhem ${ }^{3,4}$, Anna Mia Ekström, \\ and Lars E. Eriksson ${ }^{1,4,6^{*}}$ (1)
}

\begin{abstract}
Background: Valid and reliable instruments for the measurement of enacted, anticipated and internalised stigma in people living with HIV are crucial for mapping trends in the prevalence of HIV-related stigma and tracking the effectiveness of stigma-reducing interventions. Although longer instruments exist, e.g., the commonly used 40-item HIV Stigma Scale by Berger et al., a shorter instrument would be preferable to facilitate the inclusion of HIV stigma in more and broader surveys. Therefore, the aim of this work was to develop a substantially shorter, but still valid, version of the HIV Stigma Scale.
\end{abstract}

Methods: Data from a psychometric evaluation of the Swedish 40-item HIV Stigma Scale were reanalysed to create a short version with 12 items (three from each of the four stigma subscales: personalised stigma, disclosure concerns, concerns with public attitudes and negative self-image). The short version of the HIV stigma scale was then psychometrically tested using data from a national survey investigating stigma and quality of life among people living with HIV in Sweden ( $n=880$, mean age 47.9 years, $26 \%$ female).

Results: The hypothesized factor structure of the proposed short version was replicated in exploratory factor analysis without cross loadings and confirmatory factor analysis supported construct validity with high standardised effects $(>0.7)$ of items on the intended scales. The $X^{2}$ test was statistically significant $\left(X^{2}=154.2, \mathrm{df}=48\right.$, $p<0.001$ ), but alternate fit measures indicated acceptable fit (comparative fit index: 0.963, Tucker-Lewis index: 0.950 and root mean square error of approximation: 0.071). Corrected item-total correlation coefficients were $>0.4$ for all items, with a variation indicating that the broadness of the concept of stigma had been captured. All but two aspects of HIV-related stigma that the instrument is intended to cover were captured by the selected items in the short version. The aspects that did not lose any items were judged to have acceptable psychometric properties. The short version of the instrument showed higher floor and ceiling effects than the full-length scale, indicating a loss of sensitivity in the short version. Cronbach's a for the subscales were all >0.7.

Conclusions: Although being less sensitive in measurement, the proposed 12-item short version of the HIV Stigma Scale has comparable psychometric properties to the full-length scale and may be used when a shorter instrument is needed.

Keywords: HIV, Instrument, Nursing, Patient-reported outcome measures, Psychometrics, Short-form, Stigma

\footnotetext{
* Correspondence: lars.eriksson@ki.se

'Department of Learning, Informatics, Management and Ethics, Karolinska

Institutet, SE-171 77 Stockholm, Sweden

${ }^{4}$ Department of Infectious Diseases, Karolinska University Hospital, SE-141 86

Stockholm, Sweden

Full list of author information is available at the end of the article
} 


\section{Introduction}

HIV-related stigma is prevalent in many parts of the world and affects the quality of life of people living with HIV [1-4]. HIV-related stigma is also a common barrier to HIV testing and treatment adherence [5-10]. Valid and reliable instruments for the measurement of enacted, anticipated and internalised stigma in people living with HIV are crucial for mapping trends in the prevalence of HIV-related stigma [10]. There are several instruments designed to measure HIV stigma, where Berger et al.'s [11] 40-item HIV Stigma Scale is the most commonly used and is one of only a few instruments that cover all stigma mechanisms affecting people with HIV [10]. We recently adapted and validated this scale for the Swedish context and, after removing one item, a 39-item scale showed satisfactory construct validity and reliability [12]. The over-determination of the full-length scales, with high Cronbach's $\alpha$ (0.883-0.958), indicated that the number of items could be reduced. Furthermore, the original 40 -item scale may take up to $25 \mathrm{~min}$ to complete [13]. Shortened versions, which respectively cover 25 and 32 items of the HIV Stigma Scale, have been published previously $[13,14]$. However, to facilitate the inclusion of HIV stigma in more extensive surveys, a shorter instrument would be preferable. Although short forms exist for children and young adults [15-17], beyond the abovementioned examples, no other shorter versions of the HIV Stigma Scale have been published for adults living with HIV. The aim of this work was therefore to develop a substantially shorter version of the HIV Stigma Scale with psychometric properties retained from the full-length scale.

\section{Methods}

The short version of the HIV Stigma Scale was developed in two phases: 1) Our data from the validation of the 40item HIV Stigma Scale in Sweden $(n=132,55$ female, 77 male, age 23-74; mean 48.3, SD 11.0) [12] were reanalysed in order to select items for a short version. 2) To ensure construct validity and reliability of the shorter version, psychometric analysis was also performed on data from an additional sample who had responded to our proposed short version of the HIV Stigma Scale.

\section{Phase 1. Item reduction}

The HIV Stigma Scale consists of four subscales intended to measure personalised stigma, disclosure concerns, concerns with public attitudes and negative self-image [11]. Berger et al. [11] described that each of these subscales contains between two and three main aspects, as summarised

Table 1 Main aspects of subscales and items selected for the short version of the HIV Stigma Scale

\begin{tabular}{|c|c|c|c|}
\hline Subscale & $\begin{array}{l}\text { Description of content excerpted } \\
\text { from Berger et al. }{ }^{a}\end{array}$ & Interpretation of main aspects & $\begin{array}{l}\text { Questions selected for the short } \\
\text { version of the HIV Stigma Scale }\end{array}$ \\
\hline \multirow[t]{4}{*}{$\begin{array}{l}\text { Personalised } \\
\text { stigma }\end{array}$} & \multirow{4}{*}{$\begin{array}{l}\text { '...Perceived consequences of other people } \\
\text { knowing that the respondent has HIV, such } \\
\text { as losing friends, feeling that people were } \\
\text { avoiding him/her, and regrets for having } \\
\text { told people'. }\end{array}$} & 1. Losing friends and fear of rejection. & $\begin{array}{l}\text { 29. People I care about stopped calling } \\
\text { after learning I have HIV }\end{array}$ \\
\hline & & & $\begin{array}{l}\text { 36. I have lost friends by telling them I } \\
\text { have HIV }\end{array}$ \\
\hline & & 2. Feeling that people avoid me. & $\begin{array}{l}\text { 28. Some people avoid touching me if } \\
\text { they know I have HIV }\end{array}$ \\
\hline & & $\begin{array}{l}\text { 3. Regrets for having told people } \\
\text { about my HIV status }\end{array}$ & $\begin{array}{l}\text { All items regarding this aspect cross-loaded } \\
\text { in analyses or had underfit }\end{array}$ \\
\hline \multirow{4}{*}{$\begin{array}{l}\text { Disclosure } \\
\text { concerns }\end{array}$} & \multirow{4}{*}{$\begin{array}{l}\text { '... controlling information, keeping one's } \\
\text { HIV status a secret, or worrying that others } \\
\text { who knew about respondent's HIV status } \\
\text { would tell'. }\end{array}$} & 1. Keeping my HIV status a secret & 4. Telling someone I have HIV is risky \\
\hline & & & 6. I work hard to keep my HIV a secret \\
\hline & & & $\begin{array}{l}\text { 17. I am very careful who I tell that I } \\
\text { have HIV }\end{array}$ \\
\hline & & $\begin{array}{l}\text { 2. Worrying that others will disclose } \\
\text { my HIV status }\end{array}$ & $\begin{array}{l}\text { All items regarding this aspect cross-loaded } \\
\text { in the analyses or had underfit }\end{array}$ \\
\hline \multirow[t]{3}{*}{$\begin{array}{l}\text { Concerns about } \\
\text { public attitudes }\end{array}$} & \multirow{3}{*}{$\begin{array}{l}\text { '... what most people think about people } \\
\text { with HIV or what most people with HIV } \\
\text { can expect when others learn } \\
\text { they have HIV ... the consequences of people } \\
\text { in general knowing about a person having HIV'. }\end{array}$} & $\begin{array}{l}\text { 1. What most people think about } \\
\text { people with HIV }\end{array}$ & $\begin{array}{l}\text { 10. Most people believe a person who } \\
\text { has HIV is dirty }\end{array}$ \\
\hline & & & $\begin{array}{l}\text { 20. Most people are uncomfortable } \\
\text { around someone with HIV }\end{array}$ \\
\hline & & $\begin{array}{l}\text { 2. Consequences of people in general } \\
\text { knowing about a person having HIV }\end{array}$ & $\begin{array}{l}\text { 9. People with HIV are treated like } \\
\text { outcasts }\end{array}$ \\
\hline \multirow[t]{3}{*}{$\begin{array}{l}\text { Negative } \\
\text { self-image }\end{array}$} & \multirow{3}{*}{$\begin{array}{l}\text { '... feeling unclean, not as good as others } \\
\text { or like a bad person because of HIV ... } \\
\text { feelings of shame and guilt'. }\end{array}$} & $\begin{array}{l}\text { 1. Negative feelings, guilt, shame, } \\
\text { feeling unclean }\end{array}$ & 2. I feel guilty because I have HIV \\
\hline & & $\begin{array}{l}\text { 2. Feeling like I am a bad person } \\
\text { because of HIV }\end{array}$ & $\begin{array}{l}\text { 7. I feel I'm not as good a person as } \\
\text { others because I have HIV }\end{array}$ \\
\hline & & & $\begin{array}{l}\text { 3. People's attitudes about HIV make } \\
\text { me feel worse about myself }\end{array}$ \\
\hline
\end{tabular}


in Table 1. The intention when developing a short version of the HIV Stigma Scale was to select items in the instrument that showed good psychometric properties, but also to maintain as many as possible of the aspects of HIV stigma that the original instrument was intended to cover. The item reduction process is presented schematically in Fig. 1 and in more detail below.

\section{Step 1. Removing items with underfit}

All items in the full-length scale were examined with item response theory methods to find items with underfit [18]. Partial credit models were calculated for each subscale separately using the package eRm [19] in R statistics [20] and item fit statistics were assessed. Items with outfit or infit mean square values exceeding 1.2 were considered to have underfit [18] and were not considered for the short version of the HIV stigma scale.

\section{Step 2. Removing cross-loading items}

Remaining items were evaluated regarding their loading in our previously published exploratory factor analysis performed on data from 132 persons living with HIV in Sweden [12]. Cross loading items were not considered for the short version of the HIV stigma scale.

\section{Step 3. Keeping as many aspects as possible}

A group of professionals working in academia and HIV care and with expertise in HIV and psychometrics discussed which of the remaining items best represented the different aspects of HIV stigma that Berger et al. [11] intended the instrument to cover. They agreed on three selected items from each of the four subscales to be included in the Phase 2 assessment of a tentative 12-item short version of the HIV Stigma Scale. The same response format from the original scale was used, i.e. a 4-point Likert scale, ranging from strongly disagree (1) to strongly agree (4). Responses were summed to calculate subscale scores with a possible range of 3 to 12; higher scores reflect a higher level of perceived HIV-related stigma.

\section{Phase 2. Psychometric evaluation of the short version of the HIV stigma scale}

The proposed short version of the HIV Stigma Scale was distributed as part of a longer self-administered anonymous questionnaire to a sample of individuals participating in the nationwide study 'Living with HIV in Sweden' [21]. This nationwide study investigated the quality of life of people living with HIV in Sweden and was performed December 2013 through August 2014.

\section{Participants}

The inclusion criteria were as follows: 1) $>18$ years of age and 2) having been diagnosed with HIV $>6$ months. Participants were recruited consecutively at 15 different centres for HIV care across Sweden, resulting in a total of 1096

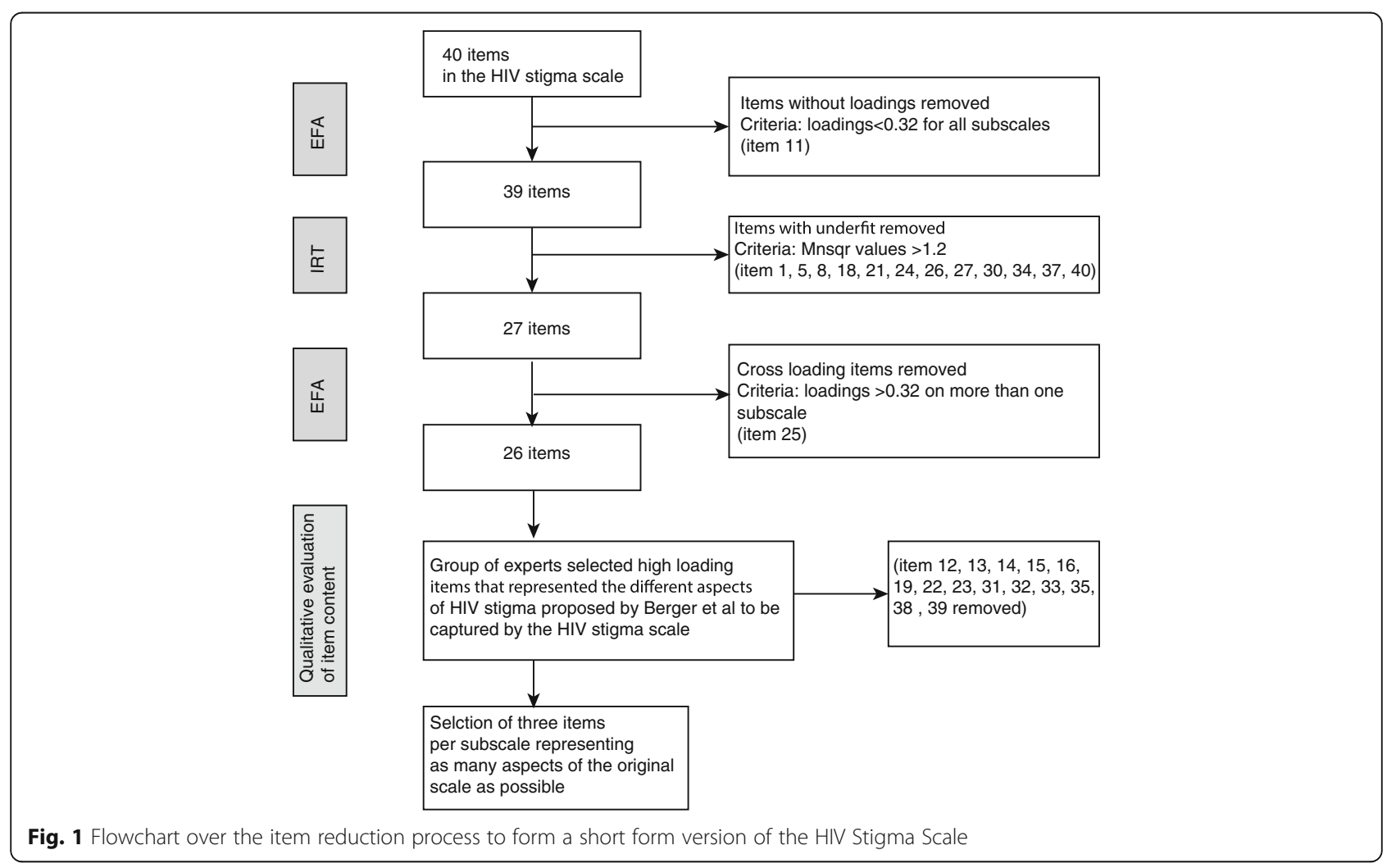


Table 2 Factor loadings ${ }^{a}$ and outfit/infit mean square measures ${ }^{b}$ for all items in the HIV stigma scale

\begin{tabular}{|c|c|c|c|c|c|c|}
\hline \multirow[t]{2}{*}{ Items } & \multicolumn{4}{|c|}{ Component } & \multirow[t]{2}{*}{ Outfit Msqr } & \multirow[t]{2}{*}{ Infit Msq } \\
\hline & 1 & 2 & 3 & 4 & & \\
\hline 39. People seem afraid of me once they learn I have HIV & 0.866 & & & & 0.485 & 0.511 \\
\hline 29. People I care about stopped calling after learning I have HIV & 0.864 & & & & 0.592 & 0.661 \\
\hline 38. People who know I have HIV tend to ignore my good points & 0.833 & & & & 0.530 & 0.557 \\
\hline 28. People avoid touching me once they know I have HIV & 0.824 & & & & 0.654 & 0.748 \\
\hline $\begin{array}{l}\text { 35. I have stopped socializing with some people due to their } \\
\text { reaction to me having HIV }\end{array}$ & 0.776 & & & & 0.641 & 0.702 \\
\hline 36. I have lost friends by telling them I have HIV & 0.770 & & & & 0.748 & 0.869 \\
\hline $\begin{array}{l}\text { 33. People have physically backed away from me when they learn } \\
\text { I have HIV }\end{array}$ & 0.726 & & & & 0.729 & 0.735 \\
\hline 24. I have been hurt by how people reacted to learning I have HIV & 0.721 & & & & 1.337 & 1.267 \\
\hline $\begin{array}{l}\text { 32. People don't want me around their children once they know I } \\
\text { have HIV }\end{array}$ & 0.714 & & & & 0.975 & 1.013 \\
\hline $\begin{array}{l}\text { 30. Some people told me that getting HIV is what I deserve for } \\
\text { how I have lived my life }\end{array}$ & 0.700 & & & & 1.164 & 1.383 \\
\hline 27. As a rule, telling others that I have HIV has been a mistake & 0.677 & 0.344 & & & 1.159 & 1.205 \\
\hline $\begin{array}{l}\text { 31. Some people close to me are afraid others will reject them if } \\
\text { it becomes known that I have HIV }\end{array}$ & 0.671 & & & & 1.093 & 1.101 \\
\hline 26. I regret having told some people that I have HIV & 0.642 & 0.327 & & & 1.680 & 1.505 \\
\hline 34. Some people act as though it's my fault I have HIV & 0.638 & & & & 1.212 & 0.881 \\
\hline $\begin{array}{l}\text { 40. When people learn you have HIV, they look for flaws in your } \\
\text { character }\end{array}$ & 0.627 & & & & 1.262 & 0.978 \\
\hline 18. Some people who know I have HIV have grown more distant & 0.604 & & & & 1.999 & 1.456 \\
\hline 6. I work hard to keep my HIV a secret & & 0.751 & & & 0.580 & 0.627 \\
\hline 17. I am very careful who I tell that I have HIV & & 0.746 & & & 0.637 & 0.686 \\
\hline 1. In many areas of my life, no one knows I have HIV & & 0.696 & & & 1.559 & 1.142 \\
\hline 21. I never feel I need to hide the fact I have HIV (R) & & 0.575 & -0.411 & & 1.334 & 1.291 \\
\hline 4. Telling someone I have HIV is risky & & 0.614 & & & 0.870 & 0.804 \\
\hline 25. I worry people who know I have HIV will tell others & 0.362 & 0.542 & & & 0.841 & 0.858 \\
\hline 22. I worry that people may judge me when they learn I have HIV & & 0.493 & & & 0.763 & 0.733 \\
\hline $\begin{array}{l}\text { 37. I have told people close to me to keep the fact that I have } \\
\text { HIV a secret }\end{array}$ & & 0.402 & & & 1.333 & 1.248 \\
\hline 15. Having HIV makes me feel that I'm a bad person & & & -0.737 & & 0.667 & 0.725 \\
\hline 7. I feel I'm not as good a person as others because I have HIV & & & -0.698 & & 0.738 & 0.696 \\
\hline 3. People's attitudes about HIV make me feel worse about myself & & & -0.665 & & 0.762 & 0.817 \\
\hline 8. I never feel ashamed of having HIV (R) & & & -0.654 & & 1.361 & 1.406 \\
\hline 12. Having HIV makes me feel unclean & & & -0.570 & & 0.778 & 0.790 \\
\hline 2. I feel guilty because I have HIV & & & -0.532 & & 1.105 & 1.022 \\
\hline 23. Having HIV in my body is disgusting to me & & & -0.530 & & 0.970 & 0.991 \\
\hline $\begin{array}{l}\text { 13. Since learning I have HIV, I feel set apart and isolated from } \\
\text { the rest of the world }\end{array}$ & 0.357 & & -0.484 & & 0.983 & 0.967 \\
\hline 20. Most people are uncomfortable around someone with HIV & & & & -0.769 & 0.550 & 0.560 \\
\hline 9. People with HIV are treated like outcasts & & & & -0.639 & 1.016 & 0.941 \\
\hline 14. Most people think that a person with HIV is disgusting & & & & -0.613 & 0.865 & 0.806 \\
\hline 10. Most people believe a person who has HIV is dirty & & & & -0.599 & 0.734 & 0.760 \\
\hline 16. Most people with HIV are rejected when others find out & & & & -0.598 & 1.049 & 1.076 \\
\hline
\end{tabular}


Table 2 Factor loadings ${ }^{a}$ and outfit/infit mean square measures ${ }^{b}$ for all items in the HIV stigma scale (Continued)

\begin{tabular}{l} 
5. People with HIV lose their jobs when employers find out \\
19. Since leardning I have HIV, I worry about people discriminating \\
against me \\
11. It is easier to avoid new friendship than worry about telling \\
someone \\
that I have HIV \\
\hline a Factor component scores are reproduced under the creative common licence CC-BY from our previous work Lindberg MH, Wettergren L, Wiklander M, \\
Svedhem-Johansson V, Eriksson LE. Psychometric Evaluation of the HIV Stigma Scale in a Swedish Context. PloS One. 2014;9(12):e114867 [12]. The analysis \\
was performed on 132 completed questionnaires from persons living with HIV in Sweden \\
bInfit and outfit Meansquare values calculated through Partial credit models, Item response theory. Infit/outfit msqr values >1.2 were considered to have \\
underfit (bold) \\
CItem 11 was removed from the Swedish version of the HIV stigma scale, due to low loadings on all factors, and was thus not included in the partial credit model
\end{tabular}

valid responses (response rate ranging between 36 and $70 \%$ for different centres). The recruited sample was judged to be representative of people living with HIV in Sweden [21], where the WHO UNAIDS 90-90-90 goals are met, with $78 \%$ of the population of people living with HIV being virologically suppressed [22]. In December 2015, 6946 persons diagnosed with HIV in Sweden were linked to care, which corresponds to $99.8 \%$ of all persons diagnosed with HIV in Sweden. Of these, 95.1\% were on antiretroviral therapy and $94.7 \%$ of those who had been on treatment for at least 6 months had a viral load <50 HIV-1 RNA copies/mL [22]. For the present analysis, a subsample of 880 questionnaires with complete answers to the 12-item HIV
Stigma Scale was used (age range 18-82 years, mean age $47.9,26 \%$ female).

\section{Construct validity}

The sample of 880 completed questionnaires was randomly divided into two groups of equal size, where the first part was analysed in an exploratory factor analysis and the second part in confirmatory factor analysis, to ensure factor stability. The exploratory factor analysis was performed in SPSS 23 with alpha factoring, oblimin rotation. The confirmatory factor analysis model that represented the short version of the HIV Stigma Scale was then set up and analysed with maximum likelihood

Table 3 Results from exploratory factor analysis ${ }^{a}$

\begin{tabular}{|c|c|c|c|c|}
\hline \multirow[b]{3}{*}{ Eigenvalues } & \multicolumn{4}{|c|}{ Factors $^{\mathrm{b}}$} \\
\hline & 1 & 2 & 3 & 4 \\
\hline & 5.61 & 1.50 & 1.21 & 1.01 \\
\hline \multicolumn{5}{|l|}{ Item } \\
\hline \multicolumn{5}{|l|}{ Personalised stigma } \\
\hline 29. People I care about stopped calling after learning I have HIV & 0.978 & -0.010 & -0.044 & 0.025 \\
\hline 36. I have lost friends by telling them I have HIV & 0.862 & 0.005 & -0.081 & -0.093 \\
\hline 28. Some people avoid touching me once they know I have HIV & 0.614 & -0.005 & 0.245 & 0.012 \\
\hline \multicolumn{5}{|l|}{ Disclosure concerns } \\
\hline 6. I work hard to keep my HIV a secret & -0.025 & -0.870 & -0.054 & -0.036 \\
\hline 4. Telling someone I have HIV is risky & -0.017 & -0.764 & -0.041 & -0.146 \\
\hline 17. I am very careful who I tell that I have HIV & 0.005 & -0.748 & 0.135 & 0.086 \\
\hline \multicolumn{5}{|l|}{ Concerns about public attitudes } \\
\hline 10. Most people believe a person who has HIV is dirty & -0.023 & -0.001 & 0.783 & -0.103 \\
\hline 9. People with HIV are treated like outcasts & 0.035 & 0.023 & 0.705 & -0.145 \\
\hline 20. Most people are uncomfortable around someone with HIV & 0.132 & -0.260 & 0.604 & 0.094 \\
\hline \multicolumn{5}{|l|}{ Negative self-image } \\
\hline 2. I feel guilty because I have HIV & 0.012 & -0.041 & -0.038 & -0.759 \\
\hline 3. People's attitudes about HIV make me feel worse about myself & 0.033 & -0.046 & 0.046 & -0.758 \\
\hline 7. I feel I'm not as good a person as others because I have HIV & 0.033 & 0.008 & 0.130 & -0.663 \\
\hline
\end{tabular}

aAlpha factoring, oblimin rotation on data from the study "Living with HIV in Sweden" $(n=440)$

${ }^{\mathrm{b}}$ Factor loadings $<-0.32$ or $>0.32$ in bold 
using the lavaan package [23] in R statistics [20]. Goodness of fit was evaluated using $X^{2}$ testing and was expected to be non-significant if the data had a good fit to the model; root mean square error of approximation (RMESA), where a score below 0.05 indicates good fit; and comparative fit index (CFI) and Tucker-Lewis index (TLI), with a desired value of $>0.90$ for both indexes [24]. Corrected item-total correlation coefficients were calculated for each item, which were expected to exceed 0.4 and also have a variation in range to ensure that the broadness of the measured concept had been captured by the short version of the scale [25]. Floor and ceiling effects were calculated and compared to the Swedish 39item version of the HIV Stigma Scale (where less than $15 \%$ of participants had the lowest or highest possible score [12], which is considered acceptable [26]).

\section{Reliability}

Cronbach's $\alpha$ was assessed for the subscales to ensure internal consistency and was considered acceptable if $>0.7$ [27].

\section{Results}

\section{Phase 1. Item reduction}

Step 1. Removing items with underfit.
Twelve items showed underfit (Table 2) and were removed.

Step 2. Removing cross-loading items.

One of the remaining items, item 25, cross-loaded in the exploratory factor analysis (Table 2) and was removed.

Step 3. Keeping as many aspects as possible.

From the remaining items, three items were chosen from each subscale. We chose a selection of items that covered as many aspects of the concepts as possible. If more than one item covered an aspect, the item with highest loading was chosen. The selected items and the aspects they cover are shown in Table 1. For personalised stigma and disclosure concerns, one aspect was lost in each subscale due to cross-loading items or items with underfit (regrets that a person can have over disclosing one's HIV status and worry that someone else will disclose one's HIV status).

\section{Phase 2. Psychometric evaluation of the short version of the HIV Stigma Scale \\ Construct validity}

In the exploratory factor analysis (alpha factoring, oblimin rotation) the factor structure suggested for the short version of the HIV stigma scale was replicated without cross loadings (Table 3). Eigenvalues for the four factors

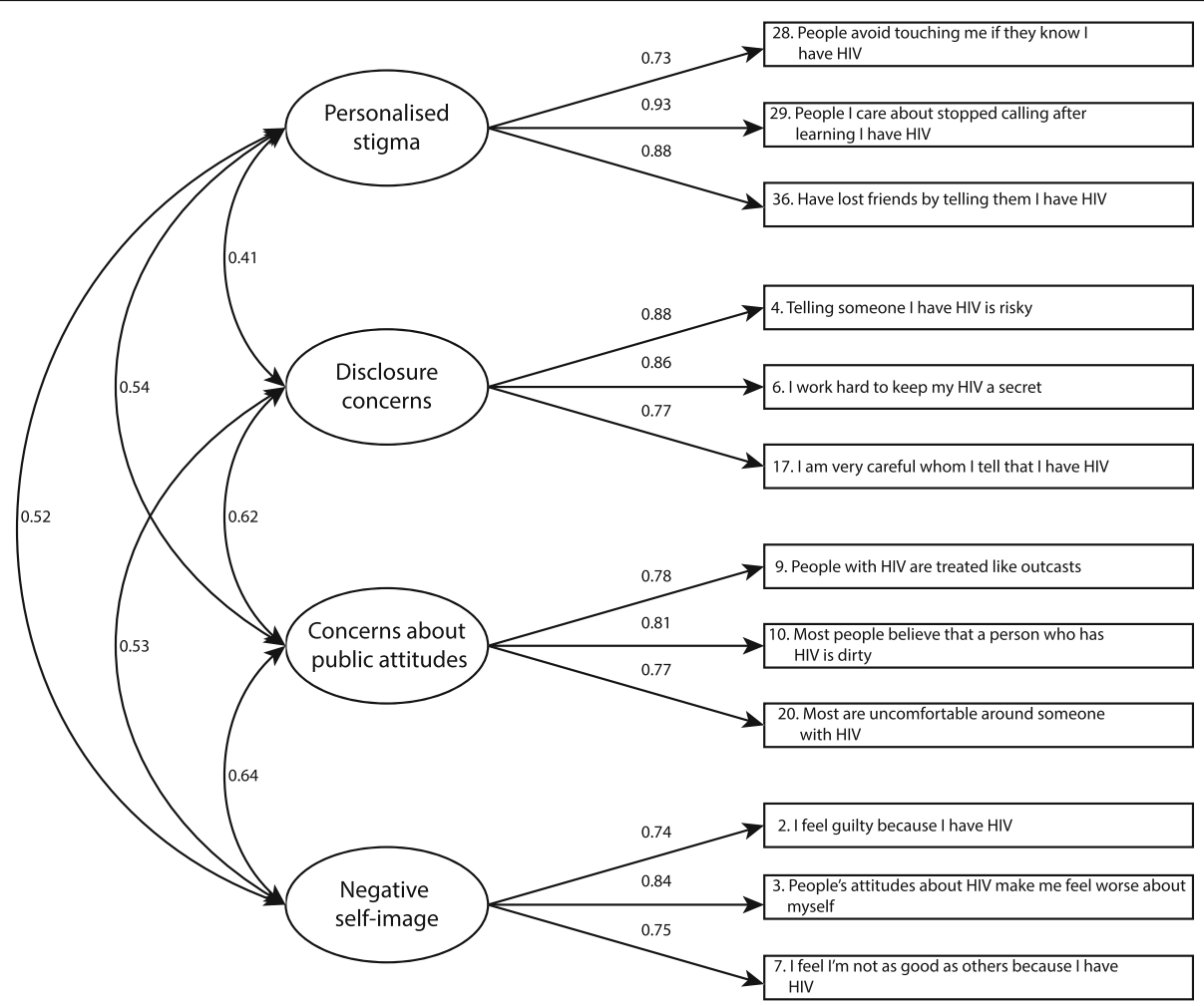

Fig. 2 Confirmatory factor analysis of the short version of the HIV Stigma Scale. Results show correlations between subscales (circles) and maximum likelihood estimates for the relation between subscales and items (squares). The sample $(n=440)$ was randomly selected from all respondents with complete answers in a Swedish population of people living with HIV. Maximum likelihood estimates are standardised 
were 5.61, 1.50, 1.21 and 1.01 respectively. Results from the confirmatory factor analysis with standardised effects and correlation coefficients are presented in Fig. 2. Construct validity of the scale was supported with high standardised effects $(>0.7)$ of items on the intended scales. The $\chi^{2}$ test was statistically significant $\left(\chi^{2}=154.2, \mathrm{df}=48\right.$, $p<0.001)$, but the alternate fit measures indicated acceptable fit; CFI: 0.963; TLI: 0.950 and RMSEA: 0.071. Descriptive statistics for the scale are presented in Table 4 on the item level and subscale level. Corrected itemtotal correlation coefficients exceeded 0.4 for all items and had a variation in the range $0.62-0.84$ (Table 4), indicating that the broadness of the intended stigma concepts had been captured. Floor or ceiling effects exceeded $15 \%$ for Personalized stigma (28\% of participants had lowest possible score), Disclosure concerns (22\% of participants had highest possible score and Negative self-image (24\% of participants had lowest possible score (Table 4).

\section{Reliability}

Cronbach's $\alpha$ for the final combination of items for the subscales were all above 0.7 and considered acceptable (Table 4).

\section{Discussion}

This report describes the development of a 12-item short version of the HIV Stigma Scale, that mainly preserves the broad concepts and internal consistency of the original subscales [11]. Since cross-loading items were excluded from the short version and no cross-loadings appeared in the exploratory factor analysis, we believe that this short version may have better psychometric properties than the original full length HIV Stigma Scale, which has exhibited overlap of items between several subscales [14]. The subscales in the short versions are highly intercorrelated, which reflects the psychometric properties of the original full length HIV stigma scale. However, a significant $\chi^{2}$ test of the confirmatory factor analysis indicated a misfit between the short version of the instrument and the data. Although it is known that even minor differences can generate a statistically significant $\chi^{2}$ value [28], we suggest further psychometric testing of the short version of the HIV stigma scale to examine whether signs of overlap of the variance between subscales will occur. Nevertheless, the other measures of model fit used, including standardised maximum likelihood estimates above 0.7 in the expected direction together with alternate fit measures within an acceptable range, supported the construct

Table 4 Descriptive statistics for items and subscales in the short-form version of the HIV Stigma Scale ${ }^{a}$

\begin{tabular}{|c|c|c|c|c|c|}
\hline & $\begin{array}{l}\text { Mean item } \\
\text { score }^{b} \text { (SD) }\end{array}$ & $\begin{array}{l}\text { Corrected item-total } \\
\text { correlation }\end{array}$ & $\begin{array}{l}\text { Mean subscale } \\
\text { score }^{c}(\mathrm{SD})\end{array}$ & Reliability, a & $\begin{array}{l}\text { Floor/ceiling } \\
\text { effect (\%) }\end{array}$ \\
\hline Personalised stigma & & & $6.09(2.75)$ & 0.88 & $28 / 6$ \\
\hline $\begin{array}{l}\text { 28. Some people avoid touching me once they } \\
\text { know I have HIV }\end{array}$ & $2.06(1.00)$ & 0.70 & & & \\
\hline $\begin{array}{l}\text { 29. People I care about stopped calling after } \\
\text { learning I have HIV }\end{array}$ & $1.97(1.00)$ & 0.84 & & & \\
\hline 36. I have lost friends by telling them I have HIV & $2.06(1.06)$ & 0.78 & & & \\
\hline Disclosure concerns & & & $9.08(2.57)$ & 0.84 & $6 / 22$ \\
\hline 4. Telling someone I have HIV is risky & $2.97(0.98)$ & 0.68 & & & \\
\hline 6. I work hard to keep my HIV a secret & $2.97(1.02)$ & 0.74 & & & \\
\hline 17. I am very careful who I tell that I have HIV & $3.25(0.96)$ & 0.68 & & & \\
\hline Concerns about public attitudes & & & $7.60(2.50)$ & 0.81 & 9/9 \\
\hline 9. People with HIV are treated like outcasts & $2.43(0.97)$ & 0.67 & & & \\
\hline $\begin{array}{l}\text { 10. Most people believe a person who has HIV } \\
\text { is dirty }\end{array}$ & $2.54(0.99)$ & 0.71 & & & \\
\hline $\begin{array}{l}\text { 20. Most people are uncomfortable around } \\
\text { someone with HIV }\end{array}$ & $2.64(0.97)$ & 0.62 & & & \\
\hline Negative self-image & & & $6.40(2.75)$ & 0.80 & $24 / 5$ \\
\hline 2. I feel guilty because I have HIV & $2.21(1.09)$ & 0.62 & & & \\
\hline $\begin{array}{l}\text { 3. People's attitudes about HIV make me feel } \\
\text { worse about myself }\end{array}$ & $2.17(1.07)$ & 0.70 & & & \\
\hline $\begin{array}{l}\text { 7. I feel I'm not as good a person as others } \\
\text { because I have HIV }\end{array}$ & $2.01(1.09)$ & 0.62 & & & \\
\hline
\end{tabular}

${ }^{\text {aParticipants with complete answers, } n=880}$

${ }^{\mathrm{b}}$ Possible score for each item 1-4; higher scores reflect a higher level of perceived HIV-related stigma

'Possible score 3-12 on each scale; higher scores reflect a higher level of perceived HIV-related stigma

SD Standard deviation 
validity of the short scale in a Swedish context; whether this holds true for different populations remains to be investigated. The sample used for testing of the proposed short version had a high proportion of men, which reflects the gender distribution of persons living with HIV in Sweden. Specific gender related properties of the instrument can therefore have been missed and should be observed in future studies.

The exploratory factor analysis that formed the basis for item selection was performed on a relatively small sample $(n=132)$. However, the overdetermined factors, together with a wide range of communalities, supported reliability of the resulting solution [29]. When choosing between using the full length scale or the developed short form, the higher floor and ceiling effects shown for the short version should be taken into account; as expected, the short version is less sensitive in detecting different levels of perceived stigma. Although less sensitive than the full-length scale, we consider the proposed 12-item short version of the HIV Stigma Scale to have essentially the same psychometric properties as the full-length scale and propose that it may be used when a shorter instrument is desirable. The short version could, for example, be used if there is a wish to include a brief stigma component in longer surveys investigating the life situation of people living with $\mathrm{HIV}$, in clinical contexts as a brief screening measure for signs of stigma-related problems or to serve as a basis for discussions with individual clients.

\section{Conclusions}

Although being less sensitive in measurement, the proposed 12-item short version of the HIV Stigma Scale has comparable psychometric properties to the full-length scale and may be used when a shorter instrument is needed.

\section{Abbreviations}

CFI: Comparative fit index; RMSEA: Root mean square error of approximation; TLI: Tucker-Lewis index

\section{Acknowledgements}

Not applicable.

\section{Availability of data and materials}

The datasets analysed during the current study are available from the corresponding author on reasonable request.

\section{Funding}

The work presented here was supported by grants from the Doctoral School in Health Care Sciences, Karolinska Institutet and the Public Health Agency of Sweden, Stockholm, Sweden. The funding bodies did not have any role in the design of the study or the collection, analysis and interpretation of data or in the writing the manuscript.

\section{Authors' contributions}

LEE, MR, LW, MW and VS conceived and designed the study; MR, MW, VS and AME contributed to the acquisition of data; MR analysed the data and drafted and revised the manuscript with assistance from LEE and LW, MW,
VS and AME all contributed to the critical revision of the manuscript. All authors read and approved the final manuscript.

\section{Competing interests}

The authors declare that they have no competing interests.

\section{Consent for publication}

Not applicable.

\section{Ethics approval and consent to participate}

The study was performed in accordance with the Declaration of Helsinki and approved by the Regional Ethical Review Board of Stockholm (record no 2013/335-32 and 2013/1552-31/4). Informed consent was obtained from all individual participants included in the study.

\section{Author details}

'Department of Learning, Informatics, Management and Ethics, Karolinska Institutet, SE-171 77 Stockholm, Sweden. ${ }^{2}$ Department of Neurobiology, Care Sciences and Society, Karolinska Institutet, SE-141 83 Stockholm, Sweden.

${ }^{3}$ Unit of Infectious Diseases, Department of Medicine Huddinge, Karolinska Institutet, SE-141 83 Stockholm, Sweden. ${ }^{4}$ Department of Infectious Diseases, Karolinska University Hospital, SE-141 86 Stockholm, Sweden. ${ }^{5}$ Department of Public Health, Karolinska Institutet, SE-171 77 Stockholm, Sweden. ${ }^{6}$ School of Health Sciences, City, University of London, ECIV OHB, London, UK.

Received: 13 December 2016 Accepted: 24 May 2017

Published online: 30 May 2017

\section{References}

1. Holzemer WL, Human S, Arudo J, Rosa ME, Hamilton MJ, Corless I, et al. Exploring HIV stigma and quality of life for persons living with HIV infection. J Assoc Nurses AIDS Care. 2009;20(3):161-8.

2. Rao D, Chen WT, Pearson CR, Simoni JM, Fredriksen-Goldsen K, Nelson K, et al. Social support mediates the relationship between HIV stigma and depression/quality of life among people living with HIV in Beijing, China. Int J STD AIDS. 2012;23(7):481-4

3. Fuster-Ruizdeapodaca MJ, Molero F, Holgado FP, Mayordomo S. Enacted and internalized stigma and quality of life among people with HIV: the role of group identity. Qual Life Res. 2014;23(7):1967-75.

4. Rydström L-L, Wiklander M, Navér L, Ygge B-M, Eriksson LE. HIV-related stigma and health-related quality of life among children living with HIV in Sweden. AIDS Care. 2016;28(5):665-71.

5. Fortenberry JD, McFarlane M, Bleakley A, Bull S, Fishbein M, Grimley DM, et al. Relationships of stigma and shame to gonorrhea and HIV screening. Am J Public Health. 2002;92(3):378-81.

6. Rintamaki LS, Davis TC, Skripkauskas S, Bennett CL, Wolf MS. Social stigma concerns and HIV medication adherence. AIDS Patient Care STDs. 2006; 20(5):359-68.

7. Sayles JN, Wong MD, Kinsler JJ, Martins D, Cunningham WE. The association of stigma with self-reported access to medical care and antiretroviral therapy adherence in persons living with HIV/AIDS. J Gen Intern Med. 2009; 24(10):1101-8.

8. Maughan-Brown B, Nyblade L. Different dimensions of HIV-related stigma may have opposite effects on hiv testing: evidence among young men and women in South Africa. AIDS Behav. 2014;18(5):958-65.

9. Sweeney SM, Vanable PA. The association of HIV-related stigma to HIV medication adherence: a systematic review and synthesis of the literature. AIDS Behav. 2016;20(1):29-50

10. Earnshaw VA, Chaudoir SR. From conceptualizing to measuring HIV stigma: a review of HIV stigma mechanism measures. AIDS Behav. 2009;13(6):1160-77.

11. Berger BE, Ferrans CE, Lashley FR. Measuring stigma in people with HIV: psychometric assessment of the HIV stigma scale. Res Nurs Health. 2001; 24(6):518-29.

12. Lindberg MH, Wettergren L, Wiklander M, Svedhem-Johansson V, Eriksson LE. Psychometric evaluation of the HIV stigma scale in a Swedish context. PLoS One. 2014;9(12):e114867.

13. Jeyaseelan L, Kumar S, Mohanraj R, Rebekah G, Rao D, Manhart LE. Assessing HIV/AIDS stigma in South India: validation and abridgement of the Berger HIV stigma scale. AIDS Behav. 2013;17(1):434-43. 
14. Bunn JY, Solomon SE, Miller C, Forehand R. Measurement of stigma in people with HIV: a reexamination of the HIV stigma scale. AIDS Educ Prev. 2007;19(3):198-208.

15. Wright K, Naar-King S, Lam P, Templin T, Frey M. Stigma scale revised: reliability and validity of a brief measure of stigma for HIV+ youth. J Adolesc Health. 2007:40(1):96-8.

16. Rongkavilit C, Wright K, Chen X, Naar-King S, Chuenyam T, Phanuphak P. HIV stigma, disclosure and psychosocial distress among Thai youth living with HIV. Int J STD AIDS. 2010;21(2):126-32.

17. Wiklander M, Rydström L-L, Ygge B-M, Navér L, Wettergren L, Eriksson LE. Psychometric properties of a short version of the HIV stigma scale, adapted for children with HIV infection. Health Qual Life Outcomes. 2013;14:11:195.

18. Bond TG, Fox CM. Applying the Rasch model : fundamental measurement in the human sciences. 2nd ed. Mahwah, NJ: Lawrence Erlbaum Associates Publishers; 2007.

19. Mair P, Hatzinger R. Extended Rasch modeling: the eRm package for the application of IRT models in R. J Stat Softw. 2007;20(9):1-20.

20. $R$ Core Team. R: A language and environment for statistical computing. $R$ Foundation for Statistical Computing. https://www.R-project.org/ /. Accessed 24 Nov 2016

21. The Public Health Agency of Sweden. Living with HIV in Sweden. 2015. https://www.folkhalsomyndigheten.se/publicerat-material/publikationsarkiv/ a/att-leva-med-hiv-i-sverige-en-studie-om-livskvalitet-hos-personer-somlever-med-hiv/. Accessed 30 Nov 2016.

22. Gisslén M, Svedhem V, Lindborg L, Flamholc L, Norrgren H, Wendahl S, et al. Sweden, the first country to achieve the joint United Nations Programme on HIV/AIDS (UNAIDS)/World Health Organization (WHO) 90-90-90 continuum of HIV care targets. HIV Med. 2017;18(4):305-7.

23. Rosseel $Y$. lavaan: an $R$ package for structural equation modeling. J Stat Softw. 2012;48(2):1-36.

24. Blunch NJ. Introduction to structural equation modeling using IBM SPSS statistics and AMOS. 2nd ed. SAGE: Los Angeles, CA; 2013.

25. Smith GT, McCarthy DM, Anderson KG. On the sins of short-form development. Psychol Assess. 2000;12(1):102-11.

26. McHorney CA, Tarlov AR. Individual-patient monitoring in clinical practice: are available health status surveys adequate? Qual Life Res. 1995;4(4):293307.

27. Tabachnick BG, Fidell LS. Using multivariate statistics. 6th ed. Pearson Education: Boston, MA; 2013

28. Vandenberg RJ, Lance CE. A review and synthesis of the measurement invariance literature: suggestions, practices, and recommendations for organizational research. Organ Res Methods. 2000;3(1):4-70.

29. MacCallum RC, Widaman KF, Zhang S, Hong S. Sample size in factor analysis. Psychol Methods. 1999:4(1):84-99.

\section{Submit your next manuscript to BioMed Central and we will help you at every step:}

- We accept pre-submission inquiries

- Our selector tool helps you to find the most relevant journal

- We provide round the clock customer support

- Convenient online submission

- Thorough peer review

- Inclusion in PubMed and all major indexing services

- Maximum visibility for your research

Submit your manuscript at www.biomedcentral.com/submit 